\title{
BMJ Open Birth cohort study on the effects of desert dust exposure on children's health: protocol of an adjunct study of the Japan Environment \& Children's Study
}

\author{
Kumiko T Kanatani, ${ }^{1}$ Yuichi Adachi, ${ }^{2}$ Nobuo Sugimoto, ${ }^{3}$ Hisashi Noma,, 5 \\ Kazunari Onishi, ${ }^{6}$ Kei Hamazaki, ${ }^{7}$ Yoshimitsu Takahashi, ${ }^{1}$ Isao Ito, ${ }^{8}$ Miho Egawa, ${ }^{9}$ \\ Keiko Sato, ${ }^{10}$ Tohshin Go, ${ }^{10}$ Youichi Kurozawa, ${ }^{6}$ Hidekuni Inadera, ${ }^{7}$ Ikuo Konishi, ${ }^{9}$ \\ Takeo Nakayama, ${ }^{1}$ Japan Environment \& Children's Study Group
}

To cite: Kanatani KT, Adachi Y, Sugimoto N, et al. Birth cohort study on the effects of desert dust exposure on children's health: protocol of an adjunct study of the Japan Environment \& Children's Study. BMJ Open 2014;4: e004863. doi:10.1136/ bmjopen-2014-004863

- Prepublication history and additional material is available. To view please visit the journal (http://dx.doi.org/ 10.1136/bmjopen-2014004863).

Received 15 January 2014

Revised 2 June 2014

Accepted 3 June 2014

CrossMark

For numbered affiliations see end of article.

Correspondence to Prof Takeo Nakayama; kanatanik@mac.com

\section{ABSTRACT}

Introduction: Desert dust is estimated to constitute about $35 \%$ of aerosol in the troposphere. Desertification, climatic variability and global warming all can contribute to increased dust formation. This study aims to examine possible health effects of desert dust exposure on pregnant women and their children. The purpose of this report was to present the study protocol.

Methods and analysis: This 4-year birth cohort study began in 2011 as an adjunct study of the Japan Environment \& Children's Study (JECS) involving three regions: Kyoto, Toyama and Tottori. The JECS participants of the three regions above who also agreed to participate in this adjunct study were enrolled prior to delivery. Light Detecting and Ranging (LIDAR) with a polarisation analyser, which can distinguish mineral dust particles from other particles, is used for exposure measurements. Outcomes are allergic symptoms for mothers and development of asthma and other allergic or respiratory diseases for their children. Data are acquired in a timely manner by connecting local LIDAR equipment to an online questionnaire system. Participants answer the online questionnaire using mobile phones or personal computers.

Ethics and dissemination: The study protocol was approved by the ethics committees of Kyoto University, University of Toyama and Tottori University. All participants provided written informed consent. The results of this study will be published in peer-reviewed journals and disseminated to the scientific community and general public.

Trial Registration number: UMIN000010826.

\section{INTRODUCTION}

\section{Desert dust and human health}

Aerosol particles are produced by a variety of natural and anthropogenic processes, with desert dust estimated to constitute about

\section{Strengths and limitations of this study}

- In this cohort study, data on environmental exposure during the period from pregnancy to early infancy, as well as potential confounding sources, are collected. A comprehensive analysis of this information will allow us to explore the role of desert dust exposure on allergic/respiratory diseases.

- Web-based questionnaires connected to an environment measurement system allows for providing the questionnaire only at necessary times, and reduces the burden on participants.

- Participants' mobile phones or personal computers are used to access the web-based questionnaires. Those who do not use either type of device were excluded. One of the weak points of the study is the lack of consistency in the type of device used to answer the questionnaires.

$35 \%$ of aerosol mass with diameter smaller than $10 \mu \mathrm{m} .{ }^{1}$ Mulitza et $a l^{2}$ reported a sharp increase in desert dust emissions that paralleled the advent of commercial agriculture in the Sahel region, suggesting that human-induced dust emissions have contributed to the atmospheric dust load for about 200 years. Desert dust particles are principally composed of rock-forming minerals such as quartz, and clay minerals such as mica and kaolinite. Additional particle analysis revealed the presence of microbial agents such as bacteria, fungi, fungal spores and viruses ${ }^{3-6}$ as well as anthropogenic atmospheric pollutants likely absorbed during transport. ${ }^{7}$

Recent evidence has revealed several possible negative effects of these dust particles 
on human health. Administration of desert dust sand to murine bronchi exerted adjuvant effects in the airway ${ }^{8} 9$ and inhalation of desert dust by patients with mild asthma caused a significant decrease in forced expiratory volume. ${ }^{10}$ Epidemiological studies showed that desert dust events were associated with health outcomes such as exacerbated asthma in Spain, the Caribbean, Japan, Korea, China, Taiwan and other locations. ${ }^{11-21}$ Although many studies on urban pollution have examined direct associations and vulnerable populations, as well as possible countermeasures and their effectiveness ${ }^{22} 23$ only a few have quantified direct associations between desert dust and human health. ${ }^{24}$ Several facets of desert dust exposure remain unknown, such as its long-term effects on healthy and vulnerable populations, who the vulnerable populations are, whether it increases the incidence of asthma or sensitisation against allergens, what components of the dust particles exert negative health effects, if there are any effect modifiers, how to reduce the effects and if it influences long-term disease progression such as outgrowing asthma. This information would be particularly important for future public health measures, because growing evidence suggests that the three main factors affecting desert dust activities-desertification, climatic variability and global warming-all can contribute to increased dust formation. ${ }^{2} 2526$

People in developed countries spend approximately $90 \%$ of their time indoors. ${ }^{27}$ We found that the arrival of Asian dust (desert dust from China and Mongolia) caused a 50-fold increase in particulate counts outdoors and a 20-fold increase indoors (in apartments) under everyday conditions, with window and air purifier use dramatically affecting indoor particulate counts. ${ }^{28}$ Minimising air pollutant exposure to reduce the risk of symptom exacerbation is viewed as a common sense solution and may lead to biased estimates of the impact of pollution exposure on health. For our cohort, we wanted to obtain information quickly on individual behaviour to lessen this bias and estimate how much risk from dust exposure can be reduced by avoidance behaviour.

\section{Mobile phone/internet use and its application to epidemiological studies}

As of 2010, 95\% of all Japanese households owned mobile phones ${ }^{29}$ and $99 \%$ of households with individuals aged 20-49 years used the internet. ${ }^{30}$ Appropriate leveraging of these web-based communication tools can enhance epidemiological research beyond conventional studies, particularly when targeting younger participants. The expected advantages over traditional methods include convenience for the participant, as well as potentially large cost savings and efficient data collection for the researcher. ${ }^{31-35}$ On the other hand, web-based surveys have several limitations, such as sampling problems, lack of participant access to computers with internet connections and internet privacy concerns. ${ }^{31} 3335$
More studies are likely needed to quantify better the risks and benefits of conducting web-based survey research. $^{31}$

Our birth cohort examines possible effects of desert dust exposure on health outcomes, using web-based questionnaires connected to an environment measurement system, allowing for the collection of information within a short time frame. This report aims to inform the relevant research community of our study objectives, design and progress.

\section{Objectives}

This study has the following objectives: (1) long-term effects; examine possible effects of desert dust exposure on the development of allergies or asthma in infants, (2) short-term effects; worsening of respiratory and allergic symptoms in pregnant women and (3) perform further analysis to examine the modification potential of long-term and short-term effects, including the degree to which the effect is lessened by avoidance behaviour, or enhanced by coexistence of other pollutants including pollen, identification of groups vulnerable to dust exposure, exploration of possible local differences in effects of desert dust exposure, and what in the dust particle exerts the effects, and to understand further the benefits and limitations of web-based questionnaires by comparing demographic characteristics between webbased survey responders and non-responders and examining the consistency of web-based answers to paperbased answers. The primary hypothesis is that the development of asthma at the age of four in those exposed to high level of desert dust is more than 1.5 times greater than those exposed to low level of desert dust.

\section{METHODS AND ANALYSIS}

\section{Setting: the Japan Environment \& Children's Study} and its adjunct study 'Effects of desert dust exposure on children's health'

The Japan Environment \& Children's Study (JECS) is an ongoing birth cohort study that began in 2011 and evaluates the impact of various environmental factors on children's health and development. A total of 100000 children and their parents took part across 15 regions in Japan $^{36} 37$ with follow-up programmes to examine health periodically from the early stages of pregnancy until the participating child reaches 13 years of age.

Exposure to environmental factors is assessed by chemical analyses of bio-specimens including blood, household environment measurements and computational simulations using monitoring data, as well as questionnaires. ${ }^{36}$ The main eligibility criteria are: (1) residence in the study areas, (2) expected delivery date between 1 August 2011 and mid-2014 and (3) capable of participating in the study without difficulty. ${ }^{36}$ The JECS allows additional investigations, or adjunct studies, pertaining to the main study. 'Effects of desert dust exposure on children's health' is our adjunct study involving three JECS regional centres in 
Kyoto, Toyama and Tottori (figure 1). These regions are located in western Japan, with Kyoto in a basin while Toyama and Tottori face the Sea of Japan. All three regions have urban, suburban and local areas, but the Kyoto region is the most urban of these three, and includes part of Kyoto city (population, 1.5 million). The Toyama region includes Toyama city (population, $420000)$, and the Tottori region includes Yonago city (population, 150000 ). There are no known area-specific air pollution problems in these regions. Asian dust is a seasonal event, and areas in western Japan, including these regions, experience yellowish air for several days in spring and autumn, when dust blows from the Asian continent. The year-average suspended particulate matter (SPM) levels in the study regions are around $15 \mu \mathrm{g} / \mathrm{m}^{3}$, and dayaverage SPM can increase up to $70 \mu \mathrm{g} / \mathrm{m}^{3}$ during Asian dust events. For PM2.5, the year-average levels in these regions are about $10-15 \mu \mathrm{g} / \mathrm{m}^{3}$, and day-average PM2.5 can increase up to $50 \mu \mathrm{g} / \mathrm{m}^{3}$ during Asian dust events and on some other days (eg, when pollutant plumes arrive from the Asian continent).

\section{Sample selection}

JECS participants in the three regions who also agreed to participate in this adjunct study were enrolled before delivery. Enrolment started in August 2011 and ended in March 2014. All participants provided written informed consent. Of the 7038 eligible pregnant women who enrolled in the JECS in Kyoto, Toyama or Tottori regional centres in 2011 and 2012, 3425 provided consent forms for this adjunct study as of the end of 2012 (figure 2). The median duration between enrolment and expected delivery was 95 days (mean, 98 days; maximum, 218 days) as of the end of 2012. Eligible participants who enrolled after 2012 were added to the study in an ongoing manner. Mobile phones/personal computers are not provided to potential participants who do not have them, in view of the high penetration of these devices in the target population.

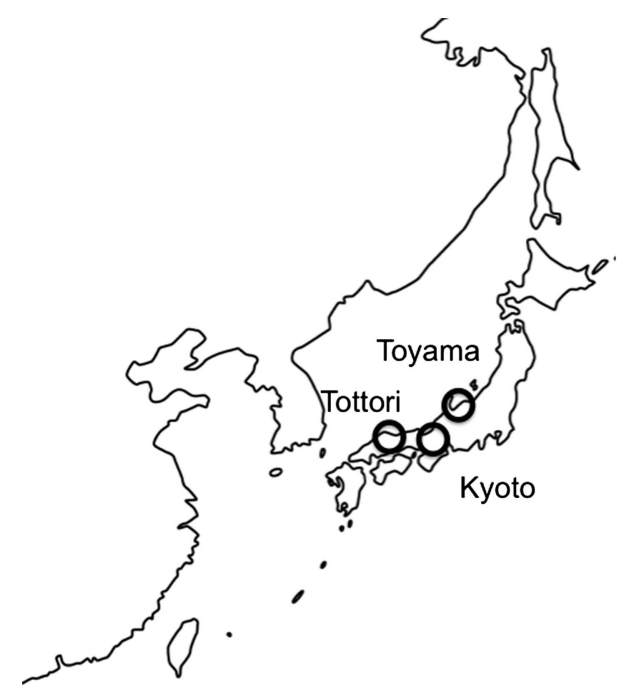

Figure 1 Investigated regions in the adjunct study.
Study design

Study design protocols are shown in figures 3 and 4 . Those who participated in the JECS at Kyoto, Toyama or Tottori regional centres were informed of this adjunct study. Those who agreed to participate were provided access to the URL for the baseline web-based questionnaire. The URL of the web-based questionnaire for assessing individual exposure level and allergic symptoms is sent to the participants' mobile phones on the day dust is observed and on some randomly selected days during the Asian dust season (February-May, and OctoberNovember). Symptom development is compared between exposed days and non-exposed days. The effect modification potential of avoidance behaviours, vulnerability characteristics and coexistence of other air pollutants including pollen are investigated using the two-factor model with interaction terms. Exposure to SPM and PM2.5, which have been used to investigate the effects of particulate matter, are also examined. Sampling of particulate matter in the air (total suspended particulate) is also conducted at each location every day during the Asian dust season, with a plan to perform chemical/biological analysis to explore what components in the dust exert the effects, or what can be effect modifiers. A web-based questionnaire for child outcomes is sent every 6 months after the child is born until the child reaches the age of 4 years. Participants answer the questionnaire using their personal mobile phones or personal computers by the set time limit (within $28 \mathrm{~h}$ after issue). The development of asthma or

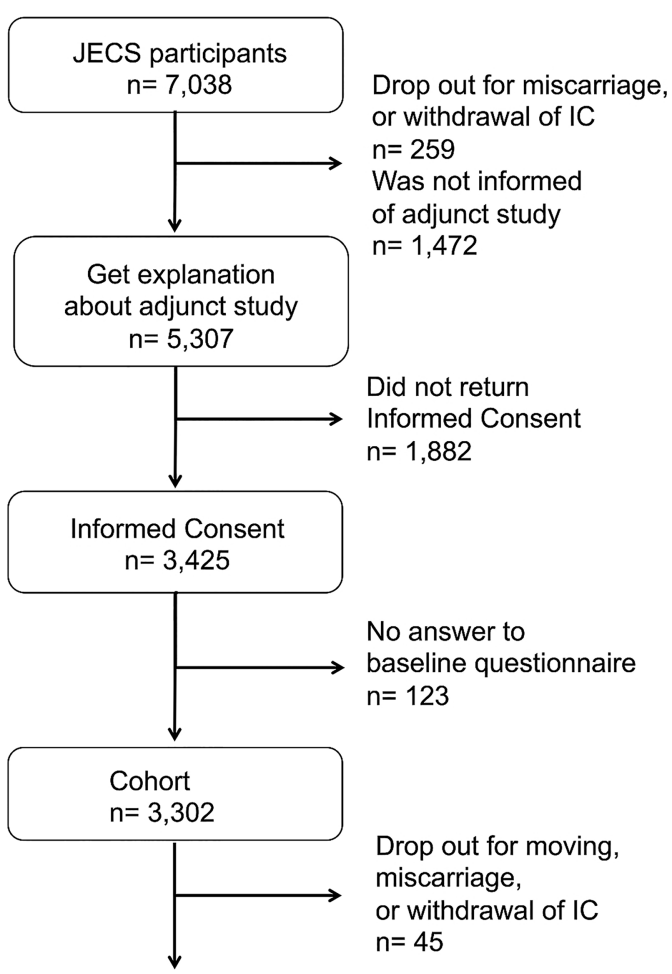

Figure 2 Participants in the Japan Environment \& Children's Study (JECS) and the adjunct study as of the end of 2012. 
other allergic diseases is compared between those exposed to high or low levels of desert dust. Time to development of asthma or other allergic diseases between the two groups is also examined.

\section{Sample size}

The primary objective of this study was to assess the association between desert dust exposure and asthma development in children. A sample of 9000 children will give $80 \%$ power to detect an OR of 1.5 at the $5 \%$ significance level between children exposed to high and low levels of desert dust, assuming the incidence of asthma in those with low exposure is $1.5 \%$. We also evaluated the sample size needed for our secondary objective, which is to assess the association between desert dust exposure and allergic symptom worsening in pregnant women, and confirmed that the sample size used for the primary objective is sufficient.

\section{Measurements}

Demographics

On study enrolment, baseline information such as history of asthma or any other allergic diseases is collected via the web-based questionnaire. In addition, various lifestyle parameters such as diet, exercise, family environment and housing environment are obtained during the course of the JECS. Serum samples are collected three times during pregnancy for the JECS, and the remaining serum will be used to measure levels of vitamin $\mathrm{D}$ and inflammatory cytokines in some participants. Details of measurement items are presented in table 1 and the questionnaire is shown in online supplementary appendix.

\section{Exposure}

Asian dust days were defined in the protocol as days during which the Light Detecting and Ranging (LIDAR) system measured more than $0.07 / \mathrm{km}$ of desert dust (day median) at an altitude of $135 \mathrm{~m}$ based on previous

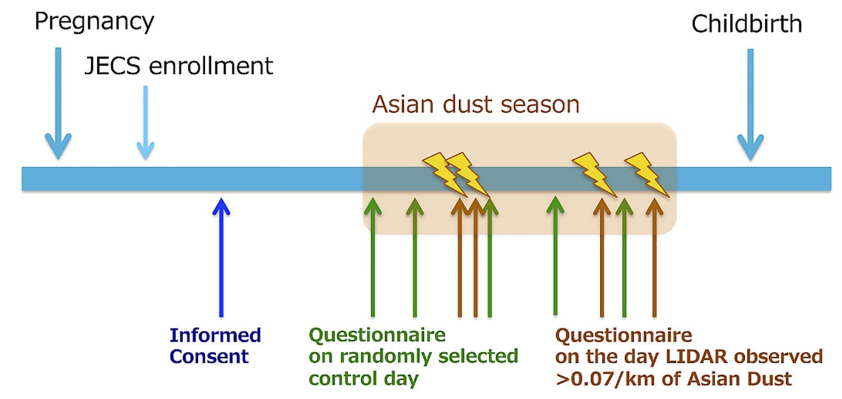

Figure 3 Adjunct study protocol during pregnancy.

A web-based questionnaire for assessing individual exposure level and allergic symptoms is issued on the day dust is observed (brown) and on some randomly selected days (green) during the Asian dust season (February-May, and October-November) (JECS, Japan Environment \& Children's Study; LIDAR, Light Detecting and Ranging). studies. ${ }^{17}{ }^{18}$ LIDAR is an optical remote sensing technology that measures properties of scattered light to obtain information on a distant target. In combination with a polarisation analyser, it can distinguish non-spherical dust particles from other spherical particles. ${ }^{17}{ }^{38-41} \mathrm{On}$ Asian dust days, a self-administered questionnaire is automatically issued to participants and the URL is sent to their mobile phones and/or personal computers. The various questions asked are shown in the online supplementary appendix. An identical questionnaire is sent for comparison on other days during the Asian dust season to randomly-selected participants with about $10 \%$ probability each day. SPM and PM2.5 are also measured at each location, and the same analysis will be performed for exposure measurements.

\section{Outcome}

For outcome measurement of allergic disease development in infants (long-term effects on infants), a selfadministered questionnaire is sent to mothers via mobile phone every 6 months after childbirth. The questionnaire includes the International Study of Asthma and Allergies in Childhood (ISAAC) questionnaire ${ }^{42}$ and physicians' diagnoses of asthma and other allergic diseases (see online supplementary appendix). We defined asthma development as persistent wheezing and/or physician's diagnosis of asthma or asthmatic bronchitis. For measurement of day-to-day symptoms (short-term effects on pregnant mothers), a self-administered questionnaire including items from a Japanese version of the Allergy Control Score ${ }^{43}$ is issued to participants via mobile phones and/or personal computers. We will compare the proportion of those with any symptom (symptom score above 0) between Asian dust days and control days.

\section{Statistical analysis plan}

(1) For the primary analysis (long-term effects on infants), we compare the development of asthma at the age of four between highly exposed and lowly exposed (lower than the first quantile and higher than the

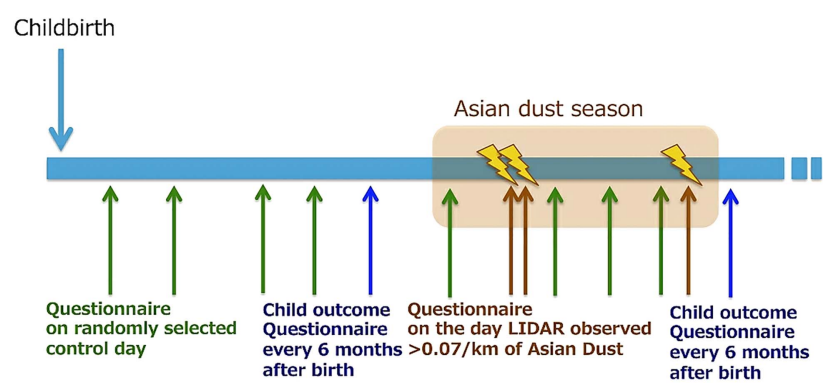

Figure 4 Adjunct study protocol after birth. A web-based questionnaire for assessing the child's exposure level is issued on the day dust is observed (brown) and on some randomly selected days (green). A web-based questionnaire for assessing child outcomes is sent every 6 months after the child is born until the child reaches 4 years of age (LIDAR, Light Detecting and Ranging). 
Table 1 Summary of adjunct study measurements and data collection items

\begin{tabular}{|c|c|}
\hline Phase & Measurements \\
\hline \multirow[t]{11}{*}{ Registration } & Expected date of childbirth \\
\hline & History of diseases including asthma and other allergic diseases (yes/no for each disease) \\
\hline & Status of asthma (clinic visit, therapy, attacks), if applicable \\
\hline & Height $(\mathrm{cm})$ and $\mathrm{BMI}^{*}$ \\
\hline & Education level ${ }^{*}$ (7 categories) \\
\hline & Family members (age and sex of other children)* \\
\hline & Family income* (10 categories) \\
\hline & $\begin{array}{l}\text { Smoking history*/partner's smoking history* }(5 \text { categories for each: never/stopped before pregnancy/ } \\
\text { stopped after pregnancy/current)/second-hand smoke exposure* }(5 \text { categories) }\end{array}$ \\
\hline & Diet status (daily intake amount of vitamins and fat in Food Frequency Questionnaire)* \\
\hline & 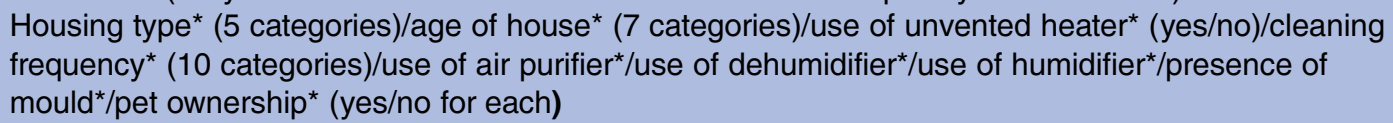 \\
\hline & Attitude towards UV exposure (3 categories) \\
\hline Pregnancy period & Hours spent outside on the day (4 categories) \\
\hline - Asian dust day & Use of mask on the day (yes/no) \\
\hline \multirow[t]{5}{*}{ - Control day } & Open or closed window on the day (yes/no) \\
\hline & Air purifier use on the day (yes/no) \\
\hline & Airing of futon/laundry on the day (yes/no for each) \\
\hline & Symptom score and medication use (Allergy Control Score) \\
\hline & Serum $25(\mathrm{OH}) D(\mathrm{ng} / \mathrm{mL}) /$ serum immunoglobulin* $(\mathrm{IU} / \mathrm{mL}) /$ inflammatory cytokines $(\mathrm{pg} / \mathrm{mL})$ \\
\hline \multirow[t]{3}{*}{ At birth } & Labour date* \\
\hline & Child's sex* \\
\hline & Attitude towards UV exposure for babies \\
\hline After birth & Hours child spent outside on the dust day (4 categories) \\
\hline - Asian dust day & Open or closed windows on the dust day (yes/no) \\
\hline \multirow[t]{2}{*}{ - Control day } & Air purifier use on the dust day (yes/no) \\
\hline & Airing of futon/laundry on the day (yes/no for each) \\
\hline \multirow[t]{3}{*}{$\begin{array}{l}\text { Every } 6 \text { months after } \\
\text { birth }\end{array}$} & $\begin{array}{l}\text { Lifetime wheezing or whistling/wheezing or whistling in the past } 6 \text { months/sleep disturbances due to } \\
\text { wheezing/clinic visits or hospitalisation for respiratory symptoms (yes/no for each) }\end{array}$ \\
\hline & Self-reported physician diagnoses of asthma and other diseases (yes/no for each) \\
\hline & UV exposure status (4 categories) \\
\hline
\end{tabular}

fourth quantile of the cumulative value of day-average dust levels from birth, respectively) infants. Time to development of asthma or other allergic diseases between the two groups is also examined applied by Cox's proportional hazards models. (2) For short-term effects on pregnant mothers, we will compare the proportion of those with any symptom (symptom score above 0) between Asian dust days (dust level $\geq 0.07 / \mathrm{km}$ ) and control days (dust level $<0.07 / \mathrm{km}$ ) for the primary analysis, and will also conduct sensitivity analysis including a comparison of the log score between these days. The generalised estimating equation is used to adjust interindividual correlations, as appropriate. (3) For further analysis to examine for possible confounders and possible effect modifiers of long-term and shortterm effects, the following factors will be examined: distance from main roads $(<30,30-50$ and $>50 \mathrm{~m})$, housing type (concrete, wooden, apartment, detached, others), age of house, use of unvented heater, cleaning frequency, use of air purifier, use of dehumidifier, use of humidifier, presence of mould in the house, pet ownership, amount of house dust, number and sex of siblings and other family members, bottle fed or breast fed, body weight at 6 months or 1 year, serum vitamin D concentration, vitamin D intake from diet and ultraviolet (UV) exposure status during pregnancy, UV exposure status after birth, socioeconomic status (income, education level), history of asthma and other allergic disease of parents, smoking in the house, local pollen level, local $\mathrm{SO}_{2}, \mathrm{NO}_{2}$ and oxygen levels, local spherical particulate level (particulates other than desert dust) and local meteorological variables (air pressure and its change from the previous day, average temperature and its change from the previous day, lowest temperature, humidity). Data will be analysed as follows: (1) each factor will be examined for the association with the outcomes using threshold models with various cut-off values, and the best model will be determined based on Quasilikelihood under the Independence model Criterion (QIC) values; (2) factors associated with the outcomes $(p<0.1)$ will be evaluated for confounder potential and/or effect modification potential by two-factor model analysis with respective interaction terms; (3) assuring that multicollinearity is not a problem, we will put all the confounders into the 


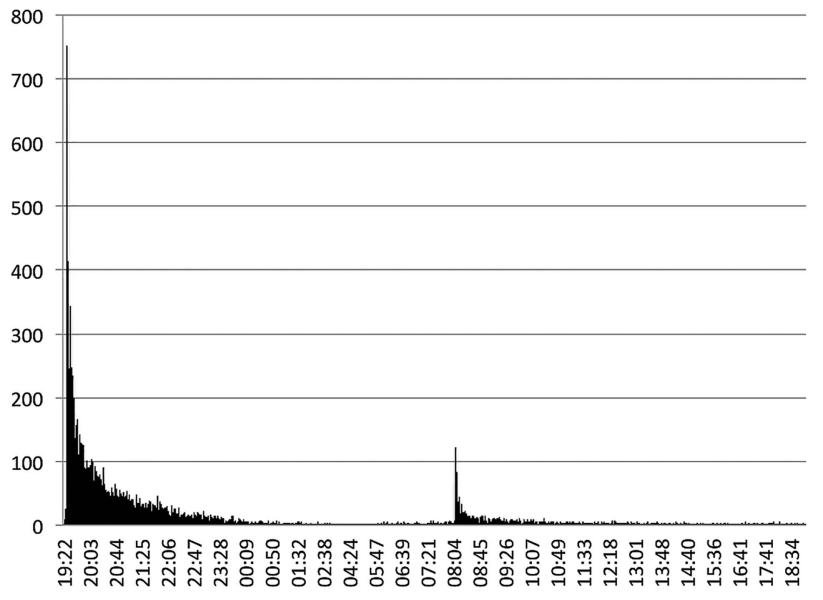

Figure 5 Distribution of answers.

desert dust model and determine the best model using a subtraction method.

\section{Progress}

Study status

We completed participant enrolment in March 2014. We will follow the children until mid-2018.

\section{Response rate}

Of those who presented consent forms to participate in this adjunct study, $3302(97 \%)$ completed the baseline questionnaire by the end of 2012. A total of 24256 questionnaires were issued in the evening on Asian dust days and control days during Asian dust seasons (OctoberNovember in 2011; February-May and OctoberNovember in 2012), and 88\% (21 345/24 256) were completed by the set time limit (within $28 \mathrm{~h}$ after issue). About half of the participants answered within $1 \mathrm{~h}$ after the email notification (questionnaire issue), and about half of the remaining participants answered within $1.5 \mathrm{~h}$ after an email reminder was sent the next morning (figure 5). Forty-five participants dropped out by the end of 2012 due mainly to moving outside the study area, withdrawal of consent or miscarriage (figure 2).

\section{DISCUSSION}

The intent of this cohort study is to collect data on environmental exposure during the period from pregnancy to early infancy and to control for potential confounding sources. Our task of collecting individual data on behaviour related to dust exposure on the same day by sending an automatic email to participants based on LIDAR system measurements was successful, as demonstrated by the high response rate of $88 \%$ as of the end of 2012. To our knowledge, this is the first study that connects an environmental measurement system to a questionnaire system, thereby reducing the burden on participants by providing the questionnaire only at necessary times.
The introduction of LIDAR data for exposure measurements in epidemiological studies is a recent endeavour. $^{17} 1821$ PM2.5 and PM10 have long been used to investigate the effects of particulate matter on health outcomes. PM2.5 and PM10 differentiate particulate size, but cannot differentiate sources, while LIDAR measurements differentiate desert dust and particulates from other sources, but do not differentiate size. ${ }^{38-41}$ In general, pollution plumes consist of a mixture of different particulate sources and sizes, making assessments of their contributions to health complicated. In this study, we will examine particulate levels from other sources, which are measured by LIDAR as spherical particulates, for possible confounders and effect modifiers. Further, SPM $(\approx \mathrm{PM} 7)$ and PM2.5 are also measured at each location, and we will conduct the same analysis for SPM and PM2.5, for comparison. These efforts will also contribute to understanding the adverse effects of particulates on health and help develop effective protection measures for vulnerable populations.

Web-based questionnaires provide benefits of an automatic validation check, automatic reminder and automatic random selection of control participants. Participant selection, however, is generally considered a significant weak point of web-based studies, particularly those that also recruit participants online. ${ }^{31}$ Our study tried to resolve this issue by recruiting participants through an ongoing cohort study that targets a relatively young population, where nearly universal internet access is achieved (about 99\%). Other concerns associated with web-based surveys include lack of participant access to computers with internet connections, internet privacy concerns and response inconsistency across different media. We attempted to overcome these issues by using participants' individual mobile phones and/or personal computers, a secure server equipped with a firewall and password protection and uploading no personal data other than email addresses on the server.

One of the limitations of our study relates to the inconsistent use of devices; some participants used mobile phones of different types, while others used personal computers. Moreover, the generalisability of the results may become a concern, given that this adjunct study follows only about one-quarter of the newborns in the study areas; those who do not use mobile phones or personal computers were excluded, and some attrition occurred mainly due to individuals moving outside the study area. However, participant characteristics as of the end of 2012 were similar overall to those reported by the Japanese government ${ }^{44-47}$ (data not shown), and only minor attrition was observed (45/3425 over the course of about a year). Thus, we believe that our cohort is representative of Japanese families with small children.

\section{Author affiliations}

${ }^{1}$ Department of Health Informatics, Graduate School of Medicine and Public Health, Kyoto University, Kyoto, Japan

${ }^{2}$ Department of Paediatrics, Faculty of Medicine, University of Toyama, Toyama, Japan

${ }^{3}$ National Institute for Environmental Studies, Tsukuba, Japan 
${ }^{4}$ The Institute of Statistical Mathematics, Tokyo, Japan

${ }^{5}$ Department of Biostatistics, Graduate School of Medicine and Public Health, Kyoto University, Kyoto, Japan

${ }^{6}$ Department of Public Health, Tottori University, Yonago, Japan

${ }^{7}$ Department of Public Health, Faculty of Medicine, University of Toyama, Toyama, Japan

${ }^{8}$ Department of Respiratory Medicine, Graduate School of Medicine, Kyoto University, Kyoto, Japan

${ }^{9}$ Department of Gynecology and Obstetrics, Graduate School of Medicine, Kyoto University, Kyoto, Japan

${ }^{10}$ Kyoto Unit Center for Japan Environment \& Children's Study, Kyoto

University, Graduate School of Medicine, Kyoto, Japan

Acknowledgements The authors would like to thank all participants of the study, Dr Atsushi Shimizu for LIDAR system support, and personnel at the following hospitals and clinics that collaborated in the JECS study: Adachi Hospital, Ekuni Ladies Clinic, Hana Clinic, Hashiba Ladies Clinic, Hayashi Maternity Clinic, Ito Hospital, Japanese Red Cross Kyoto Daini Hospital, Japanese Red Cross Society Nagahama Hospital, Kawamura Ladies Clinic, Kyoto Min-iren Chuo Hospital, Kyoto University Hospital, Kyoto Yamashiro General Medical Centre, Kyuma Women's Clinic, Mori OB/GYN Clinic, Nagahama City Hospital, Sato Clinic, Social Insurance Kyoto Hospital, Suzuki Clinic, The Japan Baptist Hospital, Toyama University Hospital, Toyama Prefectural Central Hospital, Toyama Red Cross Hospital, Okada Obstetrics Hospital, Yoshimoto Ladies Clinic, Toyama City Hospital, Saiseikai Toyama Hospital, Lady's Clinic Hosono, Kurobe City Hospital, AWANO CLINIC KANSUI-KOUEN LADIES CLINIC, Kouseiren Namerikawa Hospital, Ida Ladies Clinic, Kamazawa Maternity Clinic, Nakaso Maternity Clinic, Nagata Women's Clinic, Mio Fertility Clinic, Hakuai Hospital and Tottori University Hospital. The authors also thank Dr Kayo Ueda, Professor Akio Koizumi and Mr Takayuki Kameda for fruitful discussions.

Collaborators Kyoto Regional Centre: IK, Yukuo Konishi, TG, KS, ME, YT, Motonobu Watanabe, Reiko Yasumi, Kaori Konishi, Naoko Nakagawa, KTK, Research Coordinators and members of the JECS Kyoto Management Committee, Toyama Regional Centre: HI, KH, YA and Research Coordinators, Tottori Regional Centre: Soji Fukumoto, Ryota Teshima, Takao Inoue, YK, Tasuku Harada, Susumu Kanzaki, Yoshihiro Maegaki, Kousaku Ohno, Tatsuya Koeda, KO and Research Coordinators.

Contributors KTK, YA, NS and TN contributed to the conception, design and management of the study. HN and KTK contributed to sample size calculations and data analysis. $\mathrm{KO}, \mathrm{KH}, \mathrm{YT}, \mathrm{ME}, \mathrm{KS}, \mathrm{TG}, \mathrm{YK}, \mathrm{HI}$ and YK contributed to managing the study at each regional centre and critically revised the manuscript. All authors approved the version of the manuscript to be published.

Funding This work was supported by the Environment Research and Technology Development Fund from the Ministry of the Environment, Japan (C-1152 (2011-2013)), and a grant for the Japan Environment \& Children's Study from the Ministry of the Environment, Japan.

\section{Competing interests None.}

Patient consent Obtained.

Ethics approval The study protocol was approved by ethics committees of Kyoto University, Toyama University, and Tottori University.

Provenance and peer review Not commissioned; externally peer reviewed.

Data sharing statement Researchers interested in collaborations or further information are invited to contact KTK, MD, MAS at kanatani.

kumiko.2r@kyoto-u.ac.jp.

Disclaimer The findings and conclusions of this article are solely the responsibility of the authors and do not represent the official views of the Japanese government.

Open Access This is an Open Access article distributed in accordance with the Creative Commons Attribution Non Commercial (CC BY-NC 3.0) license, which permits others to distribute, remix, adapt, build upon this work noncommercially, and license their derivative works on different terms, provided the original work is properly cited and the use is non-commercial. See: http:// creativecommons.org/licenses/by-nc/3.0/

\section{REFERENCES}

1. Boucher O, Randall D, Cartaxo P, et al. Clouds and Aerosols. In: Climate Change 2013: The Physical Science Basis. Contribution of Working Group I to the Fifth Assessment Report of the Intergovernmental Panel on Climate Change [Stocker, T.F., D. Qin, G.-K. Plattner, M. Tignor, S.K. Allen, J. Boschung, A. Nauels, Y. Xia, V. Bex and P.M. Midgley (eds.)]. Cambridge, UK and New York, NY: Cambridge University Press, 2013.

2. Mulitza S, Heslop D, Pittauerova D, et al. Increase in African dust flux at the onset of commercial agriculture in the Sahel region. Nature 2010;d466:226-8.

3. Griffin DW. Atmospheric movement of microorganisms in clouds of desert dust and implications for human health. Clin Microbiol Rev 2007;20:459-77.

4. Chao HJ, Chan CC, Rao CY, et al. The effects of transported Asian dust on the composition and concentration of ambient fungi in Taiwan. Int J Biometeorol 2012;56:211-19.

5. Iwasaka Y, Shi GY, Yamada M, et al. Mixture of Kosa (Asian dust) and bioaerosols detected in the atmosphere over the Kosa particles source regions with balloon-borne measurements: possibility of long-range transport. Air Qual Atomos Health 2009; 2.29-38.

6. Maki T, Susuki S, Kobayashi F, et al. Phylogenetic diversity and vertical distribution of a halobacterial community in the atmosphere of an Asian dust (KOSA) source region, Dunhuang City. Air Qual Atomos Health 2008;1:81-9.

7. Choi JC, Lee M, Chun Y, et al. Chemical composition and source signature of spring aerosol in Seoul. Kor J Geophys Res 2001;106:18067-74.

8. Ichinose T, Yoshida S, Sadakane K, et al. Effects of Asian sand dust, Arizona sand dust, amorphous silica and aluminum oxide on allergic inflammation in the murine lung. Inhal Toxicol 2008;20:685-94.

9. Murphy SA, Bérubéa KA, Pooleya FD, et al. The response of lung epithelium to well characterised fine particles. Life $S c i$ 1998;62:1789-99.

10. Guputa $\mathrm{P}$, Singh $\mathrm{S}$, Kumar $\mathrm{S}$, et al. Effect of dust aerosol in patients with asthma. J Asthma 2012;49:134-8.

11. Meng ZQ, Lu B. Dust events as a risk factor for daily hospitalization for respiratory and cardiovascular diseases in Minqin, China. Atmos Environ 2007:41:7048-58.

12. Perez L, Tobias A, Querol X, et al. Coarse particles from Saharan dust and daily mortality. Epidemiology 2008;19:800-7.

13. Prospero JM, Blades E, Naidu R, et al. Relationship between African dust carried in the Atlantic trade winds and surges in pediatric asthma attendances in the Caribbean. Int J Biometeorol 2008;52:823-32.

14. Park JW, Lim YH, Kyung SY, et al. Effects of ambient particulate matter on peak expiratory flow rates and respiratory symptoms of asthmatics during Asian dust periods in Korea. Respirology 2005;10:470-6.

15. Yoo Y, Choung JT, Yu J, et al. Acute effects of Asian dust events on respiratory symptoms and peak expiratory flow in children with mild asthma. J Korean Med Sci 2008;23:66-71.

16. Rutherford S, Clark E, McTainsh G, et al. Characteristics of rural dust events shown to impact on asthma severity in Brisbane, Australia. Int J Biometeorol 1999;42:217-25.

17. Kanatani KT, Ito I, Al-Delaimy WK, et al. Desert dust exposure is associated with increased risk of asthma hospitalization in children. Am J Respir Crit Care Med 2010;182:1475-81.

18. Ueda $\mathrm{K}$, Shimizu A, Nitta $\mathrm{H}$, et al. Long-range transported Asian Dust and emergency ambulance dispatches. Inhal Toxicol 2012;12:858-67.

19. Yang CY, Tsai SS, Chang CC, et al. Effects of Asian dust storm events on daily admissions for asthma in Taipei, Taiwan. Inhal Toxicol 2005;17:817-21.

20. Hong YC, Pan XC, Kim SY, et al. Asian dust storm and pulmonary function of school children in Seoul. Sci Total Environ 2010;408:754-9.

21. Mallone SI, Stafoggia M, Faustini A, et al. Saharan dust and associations between particulate matter and daily mortality in Rome, Italy. Environ Health Perspect 2011;119:1409-14.

22. Pope CA 3rd. Air pollution and health-good news and bad. N Engl J Med 2004;351:1132-4.

23. Laumbach RJ, Kipen HM. Respiratory health effects of air pollution: update on biomass smoke and traffic pollution. J Allergy Clin Immunol 2012;129:3-11.

24. De Longueville F, Hountondji YC, Henry S, et al. What do we know about effects of desert dust on air quality and human health in West Africa compared to other regions? F Sci Total Environ 2010;409:1-8. 
25. Goudie AS. Dust storms: recent developments. J Environ Manage 2009;90:89-94.

26. Ozer P, Courel MF, Goudie AS. International year of deserts, desertification and dust. Afr Health 2006;28:3.

27. Lunden MM, Thatcher TL, Hering SV, et al. Use of time- and chemically resolved particulate data to characterize the infiltration of outdoor PM2.5 into a residence in the San Joaquin Valley. Eiviron Sci Technolo 2003;37:4724-32.

28. Kanatani KT, Okumura M, Tohno S, et al. Indoor particle counts during Asian dust events under everyday conditions at an apartment in Japan. Environ Health Prev Med 2014;19:81-8.

29. Cabinet Office, Government of Japan. Consumer Confidence Survey. [Internet] [updated 17 Apr 2013; cited 22 Sep 2007]. http:// www.esri.cao.go.jp/jp/stat/shouhi/2012/1203shouhi.html Japanese

30. Ministry of Internal Affairs and Communications, Japan. 2012 White Paper on Information and Communications in Japan. [Internet] [cited 22 Sep 2013]. http://www.soumu.go.jp/johotsusintokei/whitepaper/ eng/WP2012/chapter-4.pdf

31. Smith B, Smith TC, Gray GC, et al. When epidemiology meets the Internet: web-based surveys in the Millennium Cohort Study. Am J Epidemiol 2007;166:1345-54.

32. Ekman A, Dickman PW, Klint A, et al. Feasibility of using web-based questionnaires in large population-based epidemiological studies. Eur J Epidemiol 2006;21:103-11.

33. van Gelder MM, Bretveld RW, Roeleveld N. Web-based questionnaires: the future in epidemiology? Am J Epidemiol 2010;172:1292-8.

34. Krantz JH, Ballard J, Scher J. Comparing the results of laboratory and World Wide Web samples of the determinants of female attractiveness. Behav Res Methods Instrum Comput 1997;29:264-9.

35. Schaefer DR, Dillman DA. Development of standard e-mail methodology: results of an experiment. Public Opin Q 1998;62:378-97.

36. Kawamoto T, Nitta H, Murata K, et al. Rationale and study design of the Japan environment and children's study (JECS). BMC Public Health 2014;14:25.

37. Ministry of the Environment. Japan Environment and Children Study. [homepage on the Internet] [updated 9 Sep 2013; cited 22 Sep 2013]. http://www.env.go.jp/en/chemi/hs/jecs/
38. Shimizu A, Sugimoto N, Matsui I, et al. Continuous observations of Asian dust and other aerosols by polarization lidars in China and Japan during ACE-Asia. Geophys Res 2004;109: D1916.

39. Tatarov B, Müller D, Shin DH, et al. Lidar measurements of Raman scattering at ultraviolet wavelength from mineral dust over East Asia. Optics Express 2010;19:1569-81.

40. Kaneyasu N, Sugimoto N, Shimizu A, et al. Comparison of Lidar-derived dust extinction coefficients and the mass concentrations of surface aerosol. J Jpn Soc Atmos Environ 2012;47:285-91.

41. Sugimoto $\mathrm{N}$, Hara $\mathrm{Y}$, Shimizu A, et al. Comparison of surface observations and a regional dust transport model assimilated with Lidar Network Data in Asian Dust Event of March 29 to April 2. 2007. SOLA 2011;7:13-16.

42. Asher MI, Keil U, Anderson HR, et al. International Study of Asthma and Allergies in Childhood (ISAAC): rationale and methods. Eur Respir J 1995;8:483-91.

43. Kanatani KT, Slingsby BT, Mukaida $\mathrm{K}$ et al. Translation and linguistic validation of the Allergy-CONTROL-ScoreTM for use in Japan. Allergol Int 2013;62:337-41.

44. Ministry of Health, Labour and Welfare. The national health and nutrition survey in Japan, 2011 [Internet] [updated 6 Dec 2012; cited 22 Sep 2013]. http://www.mhlw.go.jp/bunya/kenkou/kenkou_eiyou_ chousa.html

45. Statistics Bureau, Ministry of Internal Affairs, and Communications. The population and households of Japan 2010 [Internet] [cited 22 Sep 2013]. http://www.stat.go.jp/english/data/kokusei/2010/poj/pdf/ 2010ch04.pdf

46. homepage on the Internet] [updated 9 Sep 2013; cited 22 Sep 2013]. http://www.hokenkai.or.jp/8/PDF/report872.pdf. http://www. e-stat.go.jp/SG1/estat/eStatTopPortalE.do School Health Survey. (Japanese).

47. Ministry of Internal Affairs and Communications. Japan statistical yearbook 2013. First Editorial Section, Statistical Library, Statistical Research and Training Institute. [Internet] [cited 22 Sep 2013]. http:// www.stat.go.jp/data/nihon/18.htm 